\title{
Periferia pensada em termos de falta: uma análise do campo da genética humana e médica
}

\section{Mariana Toledo Ferreira*}

\section{Resumo}

Este artigo busca discutir dimensões da relação entre centros e periferias na produção e circulação do conhecimento, a partir de um estudo de caso que se debruça sobre a área da genética humana e médica no Brasil. Para tanto, realizou-se um trabalho de campo que compreendeu a seleção de uma amostra de pesquisadores da área no Brasil, que levou à identificação dos programas de pós-graduação "de excelência", localizados em quatro universidades públicas: Universidade de São Paulo - campus Ribeirão Preto; Universidade Estadual de Campinas; Universidade Federal do Pará; e Universidade Federal do Rio Grande do Sul. Foram então realizadas 46 entrevistas semiestruturadas com pesquisadores pertencentes a essas instituições, para cuja análise utilizou-se o programa Atlas Ti. A exploração desse material permitiu analisar as representações dos pesquisadores sobre as possibilidades e limites de realizar pesquisa em um contexto disciplinar percebido como desigual, se comparado aos centros de pesquisa estrangeiros visitados em suas experiências de formação e pósdoutorado. Essas representações são expressas na ideia de uma periferia relacional, articulada em termos de falta, entendida em referência a questões institucionais, financeiras, técnicas, culturais e cognitivas. ${ }^{\circledR}$

Palavras-chave: Relações centro-periferia, Produção e circulação do conhecimento, Colaborações internacionais, Genética humana e médica, Ciência brasileira.

* Instituto Federal de Educação, Ciência e Tecnologia de Goiás, Formosa - GO, Brasil.

$\checkmark$ A pesquisa que originou este artigo contou com financiamento do CNPq. 


\title{
Periphery thought in terms of lack: an analysis of the field of human and medical Genetics
}

\begin{abstract}
This article seeks to discuss different dimensions of the relation between centers and peripheries in the production and circulation of knowledge, based on a case study of research programs of human and medical genetics in Brazil. Fieldwork included the selection of a sample of researchers in the field of human and medical genetics in Brazil, leading to the identification of graduate programs of "excellence", located in four public research universities: Universidade de São Paulo - campus Ribeirão Preto; Universidade Estadual de Campinas; Universidade Federal do Pará, and Universidade Federal do Rio Grande do Sul. Forty-six semi-structured interviews were held with researchers belonging to the institutions hosting these programmes, after which the software Atlas Ti was used to analyse them. Exploring this material allowed to discuss the representations of these researchers about the possibilities and limits to conduct research in a disciplinary context perceived as unequal, compared to the foreign research centers visited in their training and postdoctoral experiences. These representations are summarized in the idea of a relational periphery, articulated in terms of lack, understood in reference to institutional, financial, technical, cultural and cognitive questions.
\end{abstract}

Keywords: Center-periphery relations; Production and circulation of knowledge; International collaborations; Human and medical genetics; Brazilian science. 


\section{Introdução}

- ste artigo visa contribuir para a reflexão sobre a produção e a circulação do conhecimento em campos científicos periféricos ${ }^{1}$. Mais especificamente, busca delinear elementos e dimensões das relações entre centros e periferias, a partir de um estudo de caso na área da genética humana e médica ${ }^{2}$, tomando por base a observação e entrevistas em laboratórios e programas de pós-graduação brasileiros. Recorro à relação centro-periferia como recurso analítico, de modo a enfatizar as relações e as assimetrias entre os diferentes contextos locais nos quais se desenvolvem as práticas científicas.

Mesmo que se considere válida a ideia de um tipo de "República da Ciência", que atravessa as fronteiras nacionais (Polanyi, 1962), isso não significa que todos os contextos locais possam ser considerados equivalentes no que diz respeito à sua inserção em uma "comunidade científica internacional" ideal. Ao contrário: faz-se evidente a existência de espaços socioinstitucionais e cognitivos que ocupam o centro do cenário no desenvolvimento de novos conhecimentos face a outros contextos cujo aporte à empresa científica parece bem mais marginal (Kreimer, 2010).

A partir de estudos baseados em indicadores quantitativos, muitos trabalhos mostraram a existência de desigualdades na produção de conhecimento: a maior parte das publicações indexadas são da América do Norte e da União Europeia, a maioria dos periódicos conceituados também

\footnotetext{
${ }^{1}$ Na seção seguinte aprofundarei a conceituação de campos científicos periféricos. Por ora, concebo a periferia em termos relacionais, podendo, portanto, apenas ser compreendida diferenciando-se do centro. Isto é, um campo científico, que em determinada relação encontra-se perifericamente situado, em outra pode desempenhar um papel central. Em virtude disso, frequentemente opto pela formulação no plural - "centros" e "periferias". ${ }^{2} \mathrm{~A}$ genética humana e médica, em termos institucionais, é uma sub área da tabela de áreas da Capes e do CNPq. Ela inclui pesquisas, sejam em doenças genéticas - doenças hereditárias monogênicas ou poligênicas e multifatoriais, que envolvem a interação entre diferentes genes e destes com fatores ambientais não-genéticos (Correa, 2002) -, sejam em genética de populações humanas, que estuda as frequências gênicas de caracteres hereditários normais e patológicos nas populações humanas (Beiguelman, 2008). Opto por adotar uma definição ampla da área, incluindo também pesquisadores em genética do câncer, imunogenética, genética molecular, entre outros. A estratégia para esta pesquisa foi selecionar todos os pesquisadores que identificaram expressamente "genética humana e médica" no campo "área de atuação" disponível na plataforma Lattes.
} 
são de lá, bem como a quase totalidade das universidades que ocupam as primeiras posições em rankings internacionais. As desigualdades dessa estrutura foram extensamente discutidas e criticadas. Paulin Hountondji (1990), por exemplo, discute como a metrópole global acumula dados (em bibliotecas, museus, bancos de dados) e, mais importante, é o local da produção de teorias e métodos, enquanto as regiões periféricas, ao contrário, são fontes de dados, coletados por viajantes da metrópole (funcionários, missionários, expedições de coleta) ou por pesquisadores locais, atuando como informantes. Boaventura de Sousa Santos (2010) enuncia uma linha abissal que a modernidade traça entre sociedades metropolitanas e territórios coloniais, entre um sistema de conhecimento imperialista e as epistemologias dos excluídos.

Mas há poucos estudos empíricos na sociologia que focam as questões colocadas pelo pensamento pós-colonial ou decolonial. Nesse sentido, meu objetivo é "ver na prática", em uma área específica de produção de conhecimento, como se desenvolvem cotidianamente os processos, escolhas estratégicas, situações, relacionamentos e detalhes concretos por meio dos quais as relações entre centros e periferias são produzidas e reproduzidas por aqueles que participam ativamente do processo de produção do conhecimento. Neste artigo mobilizo, sobretudo, as articulações discursivas utilizadas pelos entrevistados para comparar os seus contextos locais com aqueles vivenciados em experiências internacionais de formação, de pósdoutorado e de colaboração. Essas diferentes articulações são resumidas na ideia de uma periferia relacional, articulada em termos de falta, entendida em referência a questões institucionais, financeiras, técnicas, culturais e, também, cognitivas.

O artigo estrutura-se em três partes. A primeira seção discute as principais referências teóricas, cujo objetivo é mostrar como o constructo analítico de centros e periferias permanece pertinente e atual para a análise da produção e circulação do conhecimento na contemporaneidade. A seção seguinte apresenta a pesquisa de campo empreendida e fornece as principais características e justificativas para a escolha do estudo de caso na área de genética humana e médica, bem como a metodologia utilizada. Na terceira seção analisam-se com maior detalhe as comparações, mobilizadas 
pelos entrevistados/as, entre os seus contextos locais de pesquisa e aqueles vivenciados em experiências internacionais, o que permitiu a construção analítica da concepção de periferia pensada em termos de falta. A seção final sintetiza as principais conclusões da análise proposta, em particular para o entendimento das dinâmicas e relações entre centros e periferias.

\section{Centros e periferias na análise da ciência contemporânea}

A distinção entre centros e periferia é frequentemente mobilizada nos estudos latino-americanos sobre as relações entre ciência, tecnologia e sociedade. Ela está enraizada em uma longa tradição, que inicia com os trabalhos de Raúl Prebisch, que a concebe nos anos 1950 para compreender a ordem econômica em escala mundial e explicar as desigualdades entre os países. Essa distinção foi revisitada pela teoria da dependência (Cardoso; Faletto, 1970) e, a partir dos anos 1960, por analistas que estudaram o papel da ciência nos países latino-americanos, e elaboraram uma série de proposições destinadas à utilização da ciência em favor do desenvolvimento econômico e social (Varsavsky, 1976; Herrera, 1971).

Wiebke Keim (2010), inspirando-se no trabalho de Cardoso e Faletto (1970), propõe um modelo mais formalizado da distinção centro-periferia para a análise da produção do conhecimento em sociologia. Seu modelo compreende três dimensões: a primeira caracteriza a infraestrutura, a organização interna e o acesso aos recursos, enfatizando fatores extracientíficos necessários à produção de conhecimento. A segunda dimensão caracteriza as condições de existência e reprodução das temáticas científicas, em que a periferia é notadamente caracterizada por sua dependência das agendas de pesquisa definidas de maneira exógena pelo centro. A terceira dimensão, por sua vez, trata da posição e do reconhecimento internacional da produção científica de uma dada zona geográfica.

A autora utiliza essas três dimensões para identificar, respectivamente, as sociologias "desenvolvidas" ou "subdesenvolvidas", as sociologias "dependentes" ou "autônomas", e as sociologias "marginais" ou "centrais", de acordo com a posição no interior da comunidade científica internacional. Essas três dimensões enriquecem o modelo centro-periferia, ao diferenciar os determinantes materiais e institucionais, a formulação de estratégias 
científicas e as estruturas de difusão e reconhecimento científico. Entendo que essas dimensões aparecem como pertinentes à análise da genética humana e médica na medida em que permitem organizar três elementos fundamentais: as assimetrias no que tange às condições materiais; as assimetrias no desenvolvimento de teorias, métodos e técnicas; e as imagens - ou reconhecimento simbólico - que as diferentes contribuições têm no cenário internacional.

O par desenvolvimento-subdesenvolvimento evidencia a necessidade de certa base material, a existência de uma comunidade científica mais ou menos integrada, instituições de ensino e de pesquisa, um mercado de trabalho acadêmico, e de financiamento para a pesquisa. As desigualdades dessa base material são o elemento mais tematizado nos estudos sobre as ciências nas periferias. As duas outras dimensões, porém, evidenciam que o desafio consiste não apenas em dispor de infraestrutura, mas também em conseguir influenciar as definições e metodologias do trabalho acadêmico, assim como os padrões de reconhecimento.

O par dependência-autonomia diz respeito ao prestígio das teorias e métodos advindos dos centros, da autoridade conferida a esses pesquisadores, do valor superior atribuído às publicações nas revistas de destaque. Tratase da conformação a uma agenda de pesquisa formulada no centro, e da adoção dos mesmos objetos de pesquisa na periferia, o que configuraria, segundo alguns autores, uma extrema dependência dos pesquisadores da periferia em relação aos países do centro (Alatas, 2003; Hountondji, 1990; Gaillard, 1994).

O par marginalidade-centralidade descreve, segundo Keim (2010), as relações entre as comunidades científicas, e também a função que uma comunidade científica desempenha na produção global de conhecimentos. Alatas (2003), por exemplo, distingue três níveis do que seria uma divisão global do trabalho científico: 1) a divisão entre trabalho intelectual teórico e empírico; 2) a divisão entre trabalhos realizados em outros países e trabalhos realizados no próprio país; 3) a divisão entre estudos comparativos e estudos de caso isolados. Segundo este autor, as ciências sociais periféricas, no que diz respeito a uma hierarquia de conhecimentos globalmente aceita, produziriam conhecimentos de um baixo grau de abstração e de 
generalização, enquanto o centro mantém o monopólio da prestigiosa pesquisa comparativa e da elaboração de teorias generalizáveis, ou mesmo universais.

Nesses trabalhos está presente, apesar da utilização de terminologias diversas - Norte e Sul, primeiro mundo e terceiro mundo, Ocidente e Oriente -, um modelo analítico que enfatiza a formação de centros e periferias, que estruturam práticas de pesquisa e reconhecimento, enfatizando os mecanismos que tornam a produção e a circulação do conhecimento um processo desigual, privilegiando determinados espaços acadêmicos, em detrimento de outros. Os cientistas podem ser participantes ativos na produção e legitimação do conhecimento, mas também podem ver sua atividade limitada à apropriação local ou à reprodução desse conhecimento que outros produzem, podendo, ainda, ver os resultados do seu trabalho desvalorizados, com base na definição, pelos centros, do que é uma contribuição inovadora e legítima para o conhecimento (Nunes; Gonçalves, 2001).

As relações entre centro e periferia também estão presentes nos debates pós-coloniais, decoloniais, e nos chamados estudos subalternos, que vêm se destacando por suas propostas de descentramento da teoria e da modernidade. Trata-se de um movimento intelectual bastante amplo, heterogêneo, cuja discussão detalhada escapa ao escopo deste artigo. Este movimento se apresenta como elaboração da crítica pós-colonial do pensamento moderno, inaugurada com a discussão de Said (1978) sobre o Orientalismo, cujos desdobramentos incluem a tentativa de "provincializar a Europa" (Chakrabarty, 2000), ou encontrar abordagens alternativas, como os projetos de indigenous knowledge (Akiwowo, 1988).

Entre as diversas correntes, uma tem como foco a realidade latinoamericana: trata-se de autores como Walter Mignolo, Aníbal Quijano e Edgardo Lander, os quais consideram que, após o colonialismo, regiões como a América Latina continuaram expostas à colonialidade do poder (em termos políticos e econômicos) e do saber (em termos epistêmicos). Os autores se concentram nas consequências epistemológicas desse fenômeno, buscando destacar a voz e o conhecimento dos oprimidos cujo status cognitivo tem sido sistematicamente subestimado. Em linhas muito gerais, 
esse debate assume que a distribuição do poder afeta a produção do conhecimento, mas a colonialidade do conhecimento (ou seja, a posição periférica da ciência latino-americana) é considerada como um dado não problematizado (Medina, 2013).

Nota-se, ainda, a influência do pensamento pós-colonial sobre a sociologia do conhecimento (Anderson; Adams, 2008). John Law (2008), por exemplo, reconheceu que os estudos sociais da ciência e da tecnologia se focaram excessivamente na observação e análise de laboratórios e processos de produção do conhecimento situados nos centros. Mas, de modo geral, a crítica aos sistemas de conhecimento ocidentais tem sido mais acentuada do que a investigação empírica da produção e circulação do conhecimento em contextos periféricos e dos mecanismos que produzem centros e periferias. Defendo, neste artigo, que tais questões abstratas ou programáticas são passíveis de análise empírica, quando o olhar se volta para a prática concreta dos produtores de conhecimento, considerando que, fundadas em suas práticas cotidianas, as relações internacionais são produzidas e reproduzidas. Nesse sentido, trata-se de "ver na prática", a partir de uma área específica do conhecimento, como se dá a incidência e recorrência de valores e expectativas dos pesquisadores situados na periferia no que diz respeito às suas relações com os centros, de modo a compreender em mais detalhes as diferentes dimensões e complexidades das relações entre centros e periferias.

Constata-se, na literatura, algumas críticas à utilização do modelo centro-periferia. L'Hoste e Hubert (2012), por exemplo, afirmam que, por vezes, ele produz explicações deterministas para a mobilidade internacional dos pesquisadores e propõem uma inversão de perspectiva: em vez de invocar uma geografia mundial das ciências para explicar a produção e a circulação de conhecimentos, deve-se partir de estudos empíricos, a fim de produzir uma geografia das ciências contextualizada. Rigas Arvanitis (2011a) critica, igualmente, a utilização desse par conceitual, cujo objetivo é classificar todos os países nessas duas categorias fixas, o que, para ele, constitui uma empreitada fadada ao fracasso. Ao contrário, propõe as noções de "países hegemônicos" e "países não hegemônicos", que ensejariam uma abordagem mais múltipla que dual, permitindo, entre outros, escapar aos 
estigmas que acompanham a noção de periferia - pobreza, analfabetismo, pouco investimento e infraestrutura (Losego; Arvanitis, 2008).

Discutindo as diferenças de produção, circulação e legitimação do conhecimento científico entre contextos periféricos e centrais no sistema global de ciência e tecnologia, Fabrício Neves propõe abordar a relação entre centro e periferia não em um nível estrutural, mas "no âmbito fenomenológico da prática científica e das expectativas consubstanciadas em discursos" (Neves, 2014, p. 558). Nesse sentido, a ênfase de sua análise do sistema biotecnológico brasileiro volta-se a como a diferenciação centroperiferia estaria sendo utilizada pelos pesquisadores como critério de observação, diferenciando a ciência em organização de ponta/organização atrasada, pesquisa de fronteira/pesquisa convencional, valor global/valor local.

Para Neves (2014), centro e periferia se apresentam como pressupostos articuladores de distinções, que têm consequências práticas, seja por meio do reconhecimento explícito da excelência científica, dos rankings de universidades e revistas, seja por meio de processos de seleção de temas de pesquisa, métodos e teorias. Nesse sentido, Neves (2017) propõe que, antes de discutir se centros e periferias existem concretamente ou se são construções ideológicas, trata-se de pensar essas distinções a partir de processos de centralização e periferização, enraizados nos contextos de prática científica. Os processos de centralização seriam aqueles em que se valoriza positivamente o conhecimento produzido, há expectativas de reconhecimento e circulação, e criam-se condições para a universalização. Por sua vez, os processos de periferização seriam aqueles em que se atribui um valor negativo ao que e como se faz, o que conduz a expectativas de não reconhecimento e de circulação restrita dos conhecimentos produzidos. Tal proposta busca, justamente, deslocar a ênfase estrutural que os conceitos de centro e periferia possam evocar.

Como exposto acima, a distinção centro-periferia está enraizada em uma longa tradição latino-americana e, visando articular essa tradição, são esses os termos mobilizados neste artigo, de modo a discutir a produção do conhecimento na área de genética humana e médica. Analisar a produção do conhecimento em termos de centros e periferias é levar em conta 
suas hierarquias e desigualdades, e evidenciar as diversas assimetrias - de financiamento, estrutura institucional, mas também aquelas referentes à seleção de temas de pesquisa, e ao reconhecimento simbólico dos produtos e produtores do trabalho científico. A abordagem das diferentes dimensões da relação entre centros e periferias busca mesclar a discussão sobre os fatores institucionais - e estruturais - e questões processuais na produção e reprodução dessa relação. Tais abordagens não precisam ser entendidas como opostas, uma vez que sua articulação permite acentuar tanto processos de dominação, vindos de fora, e características mais estruturais, tais como discutidas nas vertentes mais diretamente inspiradas nas teorias da dependência, quanto os elementos internos, de como se estrutura a vida intelectual no contexto local, e as decisões e escolhas dos pesquisadores nele situados.

A constatação das assimetrias globais não pode velar, no entanto, a inegável heterogeneidade dos países tidos como periféricos, de um lado, e centrais, de outro, o que me faz recorrer ao uso dos termos no plural, referindo-me a "centros" e "periferias". Na prática, tanto a ciência do "centro" quanto a da "periferia" são entidades heterogêneas, que incluem uma variedade de práticas. Tanto os centros quanto as periferias são, também, fortemente hierarquizados internamente, sendo possível encontrar as mesmas distinções no interior de uma região, de um país e mesmo de uma instituição (Shinn, 1988). Centros e periferias são, aqui, tomadas como noções relacionais, e não cartográficas, o que permite abordar justamente a existência de periferias localizadas no centro, e de centros constituídos na periferia.

Mobilizar as noções de centros e periferias não significa naturalizar as desigualdades, ou converter a distinção em uma explicação determinista única das diferentes trajetórias de países e campos científicos. Para que escapemos das armadilhas essencialistas dessas dimensões, é preciso considerar que "periférica" não é uma característica intrínseca a certos países, campos, ou pesquisadores, mas uma posição relacional. Se as relações centro-periferia foram frequentemente tratadas a partir da lógica difusãorecepção (Basalla, 1967), que supõe a existência de um centro que irradia o conhecimento para as periferias, entendidas como dimensões estáticas, nesta 
pesquisa a ênfase está no plano das relações que os pesquisadores inseridos em um e outro contexto estabelecem no decorrer de suas trajetórias. Por isso, o ponto de partida deve ser a análise empírica das práticas dos produtores de conhecimento. Isso significa atentar a como os discursos de centros e periferias são organizados e reorganizados nos grupos de pesquisa, no cotidiano da produção de cientistas e de conhecimento científico (Traweek, 1992), de modo a delinear os processos, escolhas estratégicas e relacionamentos por meio dos quais essas relações são produzidas e reproduzidas por aqueles que participam ativamente do processo de produção do conhecimento.

\section{Metodologia e pesquisa de campo}

A área da genética humana e médica tem grande prestígio e legitimidade, seja nos países tidos como desenvolvidos, seja no Brasil (Meneghini; Parker, 2006). Trata-se de uma área incentivada pelas políticas científicas nacionais, como pode ser aferido por seu espaço em Institutos Nacionais de Ciência e Tecnologia (INCTs) ${ }^{3}$ e em Centros de Pesquisa, Inovação e Difusão (Cepids) ${ }^{4}$. No âmbito da Fapesp foram financiados, também, grandes projetos na área, como o Projeto Genoma Humano do Câncer, entre 1999 e 2001, e o sub-projeto Genoma Clínico do Câncer, entre 2001 e 2005.

Do ponto de vista da pesquisa aplicada à saúde, destaca-se o edital do então Ministério da Ciência e Tecnologia (MCT) e do CNPq, em 2010, visando financiar projetos de pesquisa que contribuíssem "para o avanço do conhecimento, a geração de produtos" e fornecessem "subsídios para a formulação, implementação e avaliação de ações públicas voltadas à

\footnotetext{
${ }^{3}$ A genética humana e médica está presente direta ou indiretamente em quatro INCTs: Células-Tronco em Doenças Genéticas Humanas (Instituto de Biociências, USP), Genética Médica Populacional (Hospital de Clínicas de Porto Alegre), Oncogenômica (Hospital A. C. Camargo), Células-Tronco e Terapia Celular no Câncer (Faculdade de Medicina, USP/RP). ${ }^{4} \mathrm{~A}$ área está presente nos seguintes Cepids: Centro de Terapia Celular (Faculdade de Medicina, USP/RP), Instituto de Pesquisa sobre Neurociências e Neurotecnologia (Faculdade de Ciências Médicas, Unicamp), Centro de Pesquisa sobre o Genoma Humano e CélulasTronco (Instituto de Biociências, USP) e Centro Antonio Prudente para Pesquisa e Tratamento do Câncer (Hospital A. C. Camargo).
} 
atenção em Genética Clínica no SUS"5. Do ponto de vista da atenção à saúde, há alguns programas relacionados à genética médica, sendo o mais importante o Programa Nacional de Triagem Neonatal, instituído em 2001. Em 2014, o Ministério da Saúde publicou a portaria 199, que cria a Política Nacional de Atenção Integral às Pessoas com Doenças Raras ${ }^{6}$. Com isso, o SUS visa incorporar novos exames diagnósticos e credenciar instituições para o atendimento de pacientes portadores dessas enfermidades.

Esses são alguns dos elementos que justificaram a escolha da área para a realização da pesquisa sobre as relações entre centros e periferias na produção do conhecimento. De um lado, tem-se a ideia de um caso exemplar, por ser reconhecido como prioritário pela política científica, permitindo observar o que é considerado pesquisa de ponta e investigação promissora, como modelo a ser seguido e valorizado. Assim, o caso exemplar, entendido no sentido de área prioritária, pode iluminar aspectos da complexidade das relações entre centros e periferias, para além da periferia entendida em termos de escassez de recursos, tomando como base uma área bem financiada do ponto de vista da política científica nacional. De outro lado, devido à sua dimensão mais aplicada, seja em termos de atendimento a pacientes, seja em termos de políticas públicas de saúde em genética clínica, a área permite observar tensões entre a pesquisa de ponta e a dimensão local de sua produção e utilização. A articulação da exemplaridade do caso com suas especificidades permite, por meio de uma descrição aprofundada, enunciar caraterísticas significativas, tanto gerais quanto específicas, evidenciando as relações complexas envolvidas no fenômeno estudado e na área escolhida.

Definido o estudo de caso na área de genética humana e médica, foi feito um extenso levantamento dos/das pesquisadores/as que compõem

\footnotetext{
${ }^{5}$ Edital MCT/CNPq/CT-SAÚDE № 57/2010. Disponível em: http://cnpq.br/ chamadas-publicas?p_p_id=resultadosportlet_WAR_resultadoscnpqportlet_ INSTANCE_OZaM\&id $=\overline{7} 5-\overline{3} 2-1204 \&$ detalha $=$ chamadaDetalhada \&filtro $=$ resultados. Acesso em $\overline{1}$ maio de 2018.

${ }^{6} \mathrm{O}$ conceito de doença rara utilizado pelo Ministério da Saúde é o mesmo recomendado pela OMS, ou seja, é a doença que afeta até 65 pessoas em cada 100 mil indivíduos. (Cf. Portaria no 199: http://bvsms.saude.gov.br/bvs/saudelegis/gm/2014/prt0199_30_01_2014. html). Ainda que não trate exatamente de doenças genéticas, muitas delas estão incluídas nessa definição.
} 
a área em questão, entre 2014 e 2105, a partir dos sítios eletrônicos das universidades federais e estaduais brasileiras, do Diretório de Grupos do CNPq, dos Programas de Pós-Graduação reconhecidos pela CAPES, nas listas de associados da Sociedade Brasileira de Genética e da Sociedade Brasileira de Genética Médica, e em laboratórios localizados em hospitais privados e públicos. Chegou-se então a uma amostra de 381 pesquisadores(as).

De modo a poder aprofundar o tema das relações entre centros e periferias na genética humana e médica, optou-se pela entrevista em profundidade como recurso fundamental. Diversos métodos e técnicas de pesquisa vêm sendo utilizados para estudar as relações entre centros e periferias, mas predominam os estudos que utilizam análises estatísticas de publicações e atividades científicas (Gaillard, 2010). Ainda que esses estudos mostrem, no geral, padrões desiguais no que tange à produção do conhecimento, eles concedem um papel destacado às grandes redes de pesquisa, negligenciam todo o trabalho de construção de polos locais de pesquisa e, sobretudo, não enfocam as práticas de pesquisa (Arvanitis, 2011b).

O desafio, neste trabalho, é conectar as experiências dos pesquisadores envolvidos com o processo de produção e circulação do trabalho científico aos padrões, tendências ou fatores estruturais mais gerais que influenciam essas experiências. Para essa abordagem, foram realizadas entrevistas qualitativas semiestruturadas, buscando reconstruir a trajetória de pesquisadores/as da área, enfatizando não apenas suas escolhas individuais, mas também a reconstrução dos intercâmbios sociais, colaborações de pesquisa e experiências internacionais, buscando conectá-las ao contexto de atuação profissional. A ênfase na trajetória profissional - que inclui o processo de formação - justifica-se porque a produção e circulação do conhecimento podem ser consideradas como resultado de decisões estratégicas feitas pelos pesquisadores no decorrer de suas carreiras (Medina, 2013).

Foram aventadas duas possibilidades para a escolha de pesquisadores a serem entrevistados: a seleção amostral e aleatória de pesquisadores, ou a seleção de grupos de maior peso identificados no levantamento inicial. A primeira abordagem implica maior representatividade dos dados coletados, e uma possibilidade maior de falar em termos de abrangência nacional. Ao 
mesmo tempo, ela implica uma compreensão menor das especificidades regionais e institucionais. A segunda abordagem, em contrapartida, permitiria compreender em maior detalhe as especificidades regionais e comparar o modo de fazer pesquisa, bem como o modo de inserção internacional da pesquisa. Por sua vez, selecionar grupos com grande quantidade - relativa - de pesquisadores, significa deixar de fora aqueles mais marginais no campo da genética, inseridos de forma isolada em diferentes instituições brasileiras. A segunda abordagem foi escolhida porque um dos objetivos do trabalho era analisar os detalhes e meandros das relações entre centros e periferias na área específica. Nesse sentido, foram escolhidos para as entrevistas pesquisadores de quatro instituições, que possuíam programas de excelência na área de genética ${ }^{7}$, tomando por base o relatório da Avaliação Trienal da Capes dos Programas de Pós-Graduação (2010-2012), divulgado em 2013, e a quantidade de pesquisadores da área nas instituições que abrigam esses programas de pós-graduação.

\footnotetext{
${ }^{7}$ A genética humana e médica, em termos institucionais, é considerada na tabela de áreas da Capes e do CNPq como uma subárea, dentro da área genética, que por sua vez está na grande área Ciências Biológicas. Não há programas de pós-graduação exclusivamente nessa subárea, por isso o recorte na área de genética.
} 
Tabela 1: Programas de Pós-Graduação em Genética, avaliados com nota 6 ou 7 (Avaliação 2010-2012) ${ }^{\mathbf{8}}$ e número de pesquisadores nas instituições de ensino correspondentes.

\begin{tabular}{|l|c|c|c|c|}
\hline \multicolumn{1}{|c|}{ Nome do ppg } & Nota & $\begin{array}{c}\text { Número de } \\
\text { pesquisadores(as) } \\
\text { na IES }\end{array}$ & IES & Estado \\
\hline Genética e Biologia Molecular & 7 & 25 & UFRGS & RS \\
\hline Genética e Biologia Molecular & 7 & 16 & Unicamp & SP \\
\hline Ciências Biológicas (Genética) & 6 & 23 & USP/RP & SP \\
\hline Genética e Biologia Molecular & 6 & 20 & UFPA & PA \\
\hline Ciências Biológicas (Biologia Genética) & 6 & 20 & USP/SP & SP \\
\hline Genética & 6 & 16 & UFMG & MG \\
\hline Ciências Biológicas (Genética) & 6 & 9 & UFRJ & RJ \\
\hline Ciências Biológicas (Genética) & 6 & 5 & Unesp/Botucatu & SP \\
\hline
\end{tabular}

Fonte: Plataforma Lattes e Relatório Capes de Avaliação 2010-2012. Elaboração própria.

Foram realizadas entrevistas, durante o ano de 2017, nas primeiras quatro instituições descritas na tabela. Além de terem grande quantidade de pesquisadores e contarem com programas de pós-graduação de excelência9 estas instituições têm especificidades que enriquecem o estudo de caso. A UFPA é a única instituição da lista fora do eixo Sul-Sudeste e a quarta instituição brasileira em número total de pesquisadores na área de genética humana e médica. O campus de Ribeirão Preto da USP é o local de criação da primeira residência em Genética Médica no Brasil, em 1977, no Hospital das Clínicas. Além disso, ao contrário da UFPA, em que a maior parte dos pesquisadores está situada no Instituto de Ciências Biológicas, na USP/RP a

${ }^{8} \mathrm{Na}$ avaliação do quadriênio 2013-2016, publicada no final de 2017, algumas notas se modificaram: o programa da UFRJ subiu de 6 para 7 e os programas da USP caíram de 6 para 5, assim como o da Unesp.

"Evidentemente, a definição de "excelência" na produção científica é alvo de debates e controvérsias, e assumir a avaliação da Capes como critério de excelência significa deixar de fora questões complexas relativas ao tema da avaliação, como certa padronização (Strathern, 1999), performatividade (Carlotto; Garcia, 2017), ou mesmo produtivismo. Ao mesmo tempo, ser considerado programa de excelência pela Capes significa, em princípio, maior disponibilidade de financiamento para a pesquisa e, novamente, tem-se a ideia de caso exemplar, de um modelo a ser seguido. 
filiação institucional é, majoritariamente, no Departamento de Genética da Faculdade de Medicina. Na UFRGS há destacados representantes das duas principais linhas de pesquisa da área: genética de populações humanas e genética médica. Além disso, o Serviço de Genética Médica do Hospital de Clínicas de Porto Alegre é um dos mais antigos do país, sendo desde 2004 um Centro Colaborador da Organização Pan-Americana da Saúde/ Organização Mundial da Saúde. Por fim, a Unicamp possui o primeiro departamento de genética médica da América Latina localizado em uma Faculdade de Medicina - ou seja, um caso raro de existência institucional de um departamento que não é apenas de "genética", como é o caso da USP/RP.

O recorte do trabalho de campo integrou todos os pesquisadores ligados à área de genética humana e médica, localizados em diversos departamentos e programas de pós-graduação das instituições supramencionadas. Foram realizadas 46 entrevistas, o que corresponde a cerca de $70 \%$ dos contatos realizados. O grupo de entrevistados/as não é tido como uma amostra representativa (nem aleatória). Ao mesmo tempo, os integrantes da amostra têm características similares a outros geneticistas brasileiros, apresentando diversificação suficiente para fornecer insights úteis à discussão sobre as relações entre centros e periferias. Se a amostra probabilística possibilita conhecer aspectos gerais de uma dada realidade social, o caráter exemplar e único da amostra não probabilística dá acesso a um conhecimento detalhado e circunstanciado da vida social (Deslauriers; Kérisit, 2008). Ao mesmo tempo, não sendo estatisticamente representativas do universo dos grupos de pesquisa brasileiros na área, essas instituições podem ser consideradas como exemplares das estratégias bem-sucedidas de inserção internacional. Nesse sentido, defende-se que o recorte escolhido permite discutir em termos mais gerais, para a área específica, as relações centrosperiferias, sendo possível tomá-lo como representativo no nível sociológico, e não morfológico ou estatístico.

Nas quatro instituições buscou-se entrevistar pesquisadores/as com perfis distintos de idade, sexo e trajetória profissional, pesquisadores/as com fortes colaborações internacionais - identificadas via Lattes -, mas também pesquisadores/as com relações fracas ou inexistentes fora de seu contexto 
local, bem como pesquisadores/as ligados/as tanto à biologia quanto à medicina. Além disso, mesmo esta pesquisa tendo se situado em centros de excelência, foram entrevistados agentes dominantes e não dominantes no campo, pesquisadores premiados e reconhecidos, e aqueles ainda em início de carreira e que, por vezes, inclusive, não estão inseridos em programas de pós-graduação. De um lado, em seu conjunto, esses entrevistados são vistos como o "topo" na produção do conhecimento da área; de outro, ressalta-se a heterogeneidade interna desses grupos, ainda que este artigo esteja focado em identificar algumas tendências e padrões mais gerais, a partir das falas dos entrevistados, com enfoque voltado à comparação entre centros e periferias. Foram entrevistados 14 pesquisadores da UFRGS, 13 da UFPA, 10 da USP/RP, e 09 da Unicamp. Do total, 24 dos entrevistados são do sexo feminino e 22 do sexo masculino. Trinta e um pesquisadores têm experiência internacional de longa duração (mais de seis meses) - todas em países considerados centrais -, 32 são formados em biologia, e 14 em medicina. Todos são doutores, 32 realizaram ao menos um pós-doutorado no Brasil ou no exterior. O grupo inclui desde aquele que publicou dez artigos em sua carreira até o que publicou mais de 300 .

As entrevistas foram transcritas e inseridas no software Atlas Ti para a análise qualitativa, que seguiu os procedimentos de codificação aberta da "teoria fundamentada" de Strauss e Corbin (2008), envolvendo a seleção de trechos das entrevistas, a criação de códigos e a codificação desses trechos - o que permitiu desagregar os discursos individuais e reagrupálos em subtemas específicos -, a releitura desses códigos e a recodificação dessas passagens, a partir dos novos códigos criados a partir da releitura e da comparação. Ainda que já existissem alguns temas preestabelecidos no início da análise das entrevistas, esse procedimento permitiu refinar tais noções e identificar uma série de outros elementos nas entrevistas, complexificando a análise das relações e dinâmicas entre centros e periferias.

\section{Periferia pensada em termos de falta}

Tendo contextualizado a amostra e os seus critérios de seleção, passo agora a expor e analisar os principais achados da pesquisa que me levaram a formular a concepção da periferia pensada em termos de falta. Inicialmente, 
destaca-se o papel ocupado pelas estadias no exterior para as carreiras analisadas. A maior parte dos entrevistados obteve seus primeiros diplomas no Brasil e, nesse sentido, são produtos locais. Mas, no que diz respeito ao treinamento avançado, muitos realizaram estágios doutorais, doutorados integrais e pós-doutorados em instituições dos centros. Dos 46 pesquisadores entrevistados nas quatro instituições, apenas 14 não tiveram experiência internacional de longa duração - seis meses ou mais - ainda que tenham realizado estágios curtos ou cursos.

Nas entrevistas, a comparação entre a experiência de pesquisa no contexto local e a vivência no exterior destaca, sempre, as facilidades obtidas nos locais visitados, e poucas menções são feitas a algum tipo de vantagem ou aspecto positivo da experiência brasileira. Nesse sentido, pode-se afirmar que, ao articular discursivamente as diversas características dos dois espaços, o contexto local é sempre descrito em termos de falta.

Primeiramente, faltam recursos para realizar a pesquisa: os locais visitados no exterior sempre dispõem de mais recursos, seja em termos de disponibilidade de equipamentos, seja em termos de financiamento:

Por exemplo, o sequenciador que nós discutimos antes, houve uma época que no Brasil tínhamos cinquenta, enquanto na Inglaterra tinha apenas um laboratório com 200. E aqui nós achávamos que tínhamos muitos sequenciadores, e temos mesmo! (Vinícius, USP/RP).

O destaque nessa fala está nos recursos mais escassos para a pesquisa no Brasil, quando comparado aos laboratórios visitados nas instituições dos centros. No entanto, ainda que a disparidade de recursos financeiros e equipamentos tenha sido mencionada em diversas entrevistas, a principal diferença, destacada por todos aqueles que tiveram alguma experiência internacional, diz respeito ao tempo:

Se você me pedir para dizer uma técnica que só é feita lá fora, e que aqui eu não tenho condições de fazer, é difícil. Tem. Se não tiver em meu laboratório, tem na USP de São Paulo, na Unicamp... A gente tem condições de fazer basicamente tudo que eles fazem lá fora. O problema é que ter o equipamento que permite fazer uma metodologia de ponta não garante que o desenvolvimento da sua pesquisa ocorra de maneira rápida, e que progrida de uma forma que você 
consiga competir com o que está acontecendo lá. Por quê? Porque se eu tenho o equipamento, quando eu for comprar esse reagente ele vai custar três vezes mais, ele vai demorar três vezes mais para chegar aqui. E a gente começa a lidar com alguns entraves que fazem com que a gente já saia perdendo nessa corrida (Carolina, USP/RP).

Na citação acima, de uma pesquisadora da USP de Ribeirão Preto instituição vista, nas falas de acadêmicos de outras localidades nacionais, como um contexto privilegiado em termos de infraestrutura e financiamento de pesquisa no Brasil - o que falta no país é agilidade: ainda que haja financiamento para pesquisa e equipamentos ou técnicas disponíveis no contexto local, isso não significa que a pesquisa possa andar na mesma velocidade que no laboratório estadunidense em que realizou seu pósdoutorado. Explicita-se, também, a metáfora de uma corrida, difícil de ser vencida, dados os "entraves" locais.

Entre esses entraves, o mais destacado é a dificuldade de obtenção de insumos para a pesquisa - notadamente reagentes:

Uma coisa que não evoluiu muito no Brasil é a entrega de produtos. Eu trabalho numa área que é experimental [...], então a gente precisa de reagentes, e esses reagentes são na maioria importados. Se você está nos Estados Unidos ou na Europa, você diz: "eu vou fazer um experimento hoje, eu preciso desse reagente", não tem na estante, então eu peço; no máximo em dois dias tem uma caixinha na minha bancada. Eu já tive situações aqui de reagentes que demoraram quatro - não dias! - meses, para chegar. Como uma pesquisa pode andar num tempo de competição? Porque essa área compete com o mundo, eu não estou competindo só com o Brasil, eu estou competindo com o mundo, porque a ciência é internacional. Eu falo para os estudantes: a gente está trabalhando com uma ideia que tem alguém, em algum lugar do mundo, trabalhando com a mesma coisa. Então a gente tem que andar rápido. Mas como é que você pode andar rápido com um esquema desse que nós temos aqui no Brasil? (Rafael, USP/RP).

É notável a articulação entre uma noção de competição internacional - e de corrida por descobertas e publicação - e a dificuldade percebida devido à demora da importação. As dificuldades dizem respeito ao intervalo - que pode levar meses - entre "ter uma ideia" e testá-la, mas também às 
novas ideias ou hipóteses que venham a surgir a partir desse primeiro teste, que terão de esperar para serem testadas, ou sequer serão testadas. Esse processo é descrito por outra pesquisadora da seguinte maneira:

Jamais a gente vai ter toda aquela cadeia de causa e consequência, em que um experimento vai respondendo em relação ao outro, que os grandes pesquisadores têm e publicam em grandes periódicos (Ana, UFRGS).

Essa "cadeia de causa e consequência" é colocada como responsável, ao menos em parte, pela diferença na velocidade da pesquisa nos centros, em comparação às periferias. Não à toa uma das razões mais citadas para desenvolver colaborações internacionais de pesquisa é justamente a realização mais rápida de experimentos que poderiam, em princípio, ser realizados no contexto local, de modo a poder publicar os resultados mais rapidamente.

Durante a pesquisa você sempre terá que comprar alguma coisa não prevista, porque vai aparecer um resultado que gerou uma pergunta que exige uma coisa diferente [...]. O que essas colaborações permitem hoje para nós? A gente inicia o projeto aqui, gera os primeiros resultados, e uma maneira de ser mais rápido na conclusão, principalmente quando aparecem coisas não previstas, e que se você for fazer aqui, vai levar três meses para chegar o reagente... Essas colaborações aceleram isso. Você pega um aluno e manda para lá e ele vai fazer um experimento que, muitas vezes, você é capaz de fazer aqui, mas até chegar o reagente vai demorar muito (Leandro, USP/RP).

Nesse exemplo, a colaboração internacional - mediada por alunos - permite atenuar o problema da demora na importação de insumos necessários para a realização de pesquisas em genética humana e médica. Para além do que é percebido com uma demora na importação, outros "entraves" são apresentados, como problemas de infraestrutura:

Aqui a gente tem que se preocupar com muitas questões de organização, se o equipamento está funcionando, se o técnico veio ver, e o técnico daquele equipamento sofisticado não tem no Brasil, a gente tem que mandar importar um técnico para ver se conserta o equipamento. Quanto aos equipamentos sofisticados, às técnicas sofisticadas, a gente tem acesso aqui [...]. Mas aí o equipamento quebra porque a rede de energia elétrica não é tão estável, 
então fica dando pico de energia, e aí queima o equipamento. Esse tipo de coisa você não tinha que lidar na Alemanha. E se tinha, não era o pesquisador que ficava correndo atrás para resolver (Isabela, USP/RP).

Aqui, hoje, eu tenho um freezer, que quando queima eu perco todas as minhas amostras. E lá [França] é centralizado, mas disponível. A gente tem aqui, hoje, um equipamento que é o citômetro de fluxo, que eles tinham um equivalente lá, mas era um único citômetro de fluxo para o prédio inteiro da imunologia, então a pessoa marcava um horário, ia lá, e a técnica de laboratório te auxiliava nos experimentos [...]. É um equipamento bastante complexo, que permite a análise célula por célula, e rápido. Nos custou, há dois anos, seiscentos mil dólares. Qual o limitante disso? No Brasil tu recebes verba dentro daqueles editais de infraestrutura, tu consegues comprar um equipamento desses, mas tu não tens autorização para contratar técnico. Não tem um técnico dentro da universidade capaz de manipular esse equipamento. São os estudantes que recebem treinamento, de outros estudantes que já trabalharam nisso, e vai passando um para o outro, e quando todos os estudantes terminam a pesquisa, tu ficas com um equipamento de seiscentos mil dólares ocioso (Daniel, UFRGS).

Nos exemplos acima há três questões envolvidas no que diz respeito à infraestrutura de pesquisa. A primeira diz respeito à rede elétrica - há diversos relatos de amostras que estragaram por problemas dessa ordem. A segunda diz respeito à ausência de técnicos especializados para consertar equipamentos e, sobretudo, que auxiliem na utilização dos equipamentos, fazendo com que estes fiquem a cargo dos estudantes e possam se tornar ociosos caso não haja novos alunos dispostos a aprender a operá-los ${ }^{\mathbf{1 0}}$. Por fim, os entrevistados destacam que, nos laboratórios dos centros, os pesquisadores não precisariam se preocupar em cuidar da manutenção do laboratório e da administração da pesquisa e poderiam apenas realizar o seu trabalho.

\footnotetext{
${ }^{10} \mathrm{Em}$ meu mestrado, cuja pesquisa de campo foi realizada em um centro de pesquisa em genética humana e médica na USP de São Paulo, discuto em detalhes a dinâmica e as implicações desse modelo de divisão interna do trabalho baseado em estudantes, sendo a consequência mais destacada certa intermitência das técnicas estabelecidas em laboratórios, que com alguma frequência se perdem, quando uma geração de alunos se renova (Ferreira, 2013, capítulo 4).
} 
Destaca-se, em suma, a falta de infraestrutura de apoio à pesquisa. Em contrapartida, as instituições de pesquisa dos centros são vistas como possuindo uma melhor infraestrutura de apoio e mais possibilidades de se dedicar integralmente à pesquisa o que também lhes dá condições de competição melhores. O tempo, nos centros, é visto como mais bem aproveitado, por que há mais eficiência burocrática e uma maior profissionalização, enquanto no Brasil o pesquisador deve incorporar as funções de secretaria, administração, compras e contabilidade de seu projeto.

Do que foi visto até aqui, segundo os entrevistados, fazer pesquisa no Brasil é pesquisar em um contexto de falta, ainda que de falta relativa, considerando que muitos destacam que não falta tudo: não necessariamente falta dinheiro ou equipamento, mas falta material de custeio, há "entraves burocráticos", demora, há pouco pessoal de apoio ou infraestrutura institucional para que um pesquisador possa trabalhar sem se preocupar com cada etapa necessária para a realização de uma pesquisa, da tomada de preços à prestação de contas, passando por avaliação no Conselho de Ética, produtos parados na Alfândega e freezers queimados por picos de energia.

Mas a análise da periferia pensada em termos de falta pode ser melhor compreendida a partir da fala abaixo, de uma pesquisadora discutindo uma falta de "racionalidade" na compra e utilização dos equipamentos em seu contexto de trabalho, se comparado à experiência vivida em seu pós-doutorado na Inglaterra:

Uma outra coisa muito legal que eu vi lá [na Inglaterra] era a racionalização dos recursos. Por exemplo, era um prédio grande, mas os equipamentos mais caros eram super racionalizados, eles estavam em salas que eram de uso comum, tinha cadernos para agendamento, as pessoas agendavam e cumpriam rigorosamente os horários agendados. Quando voltei, eu me lembro que uma das coisas que mais me espantou era o número de máquinas de PCR que a gente tinha aqui, em comparação com o que a gente tinha lá. A gente tinha um número muito inferior de máquinas de PCR lá. A gente tinha muito menos máquinas lá do que aqui. Só que as máquinas eram mais utilizadas, e havia uma disciplina muito forte na utilização [...]. Não tinha a duplicação que a gente tem aqui (Natalia, Unicamp). 
Mais do que a discussão sobre uma falta de racionalidade do contexto local, aqui está presente uma dimensão importante, que fortalece a construção de que a periferia é sempre analisada em termos de falta: mesmo quando o contexto local parece ter uma vantagem face ao laboratório visitado, nesse caso, uma maior quantidade de equipamentos, isso também é construído enquanto falta, são equipamentos demais, há "duplicação", falta disciplina.

Outra dimensão à qual a ideia da periferia como falta se refere é a dimensão propriamente intelectual ou científica. Os centros são descritos como efervescentes e concentrados, um espaço em que se constata uma maior "densidade": maior quantidade de pesquisadores trabalhando juntos, discussões mais profundas e, também, mais competição:

E lá [pós-doutorado nos Estados Unidos] [...] tinha a grande vantagem de ter uma concentração de massa crítica, uma concentração de equipamentos, de gente, de estudantes, o que facilita muito a troca [...]. Era muito diferente. Você tem uma densidade de discussão maior. Eram vinte pós-doutores. Vinte pós-doutores muito selecionados. Então tinha uma competição muito grande para conseguir os melhores laboratórios. É a massa crítica, a discussão científica propriamente dita (Diego, USP/RP).

No relato acima, para além da constatação de que há mais pesquisadores nos centros, é destacado um argumento adicional, a saber, a falta de interação regular no contexto local: nos centros há uma quantidade maior de pesquisadores trabalhando em um mesmo tema, e agrupados em uma mesma instituição, face a uma periferia percebida como tendo menos "massa crítica", sendo menos integrada, onde há menos seminários e discussões internas.

Os centros também são vistos como espaços em que há uma maior divisão do trabalho científico:

Eles têm uma equipe muito bem segmentada, tem a pessoa que cuida da compra do material, tem a pessoa que cuida da extração do DNA, a pessoa que prepara os reagentes para o experimento, a pessoa que cuida da parte A do experimento, a pessoa que cuida da parte B [...]. Aqui eu tenho que fazer a cotação, tenho que fazer o pedido, tenho que ligar na empresa e cobrar porque o pedido não chegou, tenho que ir no banco pagar, tenho que receber 
o reagente, tenho que coletar o DNA, tenho que preparar a vidraria... Aqui uma pessoa, num doutorado, faz, do começo ao fim, tudo sozinho. Enquanto lá tem uma equipe com oito pessoas (Danilo, Unicamp).

Nos Estados Unidos as coisas andam muito mais rápido. [...] Vou dar um exemplo: a gente estava analisando um microarranjo das aortas dos animais, e a gente viu que uma série de genes, que eram do sistema complemento, que é do sistema imune, estavam alterados, ao que a minha chefe me pegou pelo braço, na hora, subiu ao andar de cima, onde tinha um cara da imunologia que trabalhava com sistema complemento, ele tinha todos os animais knockouts para cada um dos genes do sistema imune, e ele começou a oferecer [os animais]. Aqui no Brasil, acho que como a gente tem muita função, além de ser pesquisador - tu é pesquisador, tu é professor, tu tem que receber alunos de diferentes áreas -, a gente não tem um foco tão grande num ponto específico (Gustavo, UFRGS).

Além de maior quantidade, concentração e integração, há também mais especialização entre os pesquisadores nas instituições dos centros, que, sem precisarem realizar todas as atividades exigidas do pesquisador brasileiro - notadamente as tarefas burocráticas, de manutenção e a carga docente - podem ter como foco "um ponto específico". Faltaria, então, maior especialização às periferias, tanto no âmbito específico da produção do conhecimento científico quanto da falta de profissionalização das atividades de apoio à pesquisa. Esses dois elementos explicariam por que a pesquisa no contexto local é desenvolvida mais lentamente em comparação aos centros.

Os centros são também percebidos como espaços em que há diversos seminários, pesquisadores de renome, e um cotidiano permeado por ciência. Tanto é que uma pesquisadora, que realizou seu pós-doutorado nos Estados Unidos, descreve a sua experiência em termos de "choque cultural":

É um choque cultural. O chefe do departamento de genética em Cleveland, onde eu fiz o meu primeiro pós-doc, era uma pessoa muito reconhecida porque tinha descoberto o primeiro RNA longo não codificador da inativação do cromossomo X. Era uma contribuição muito importante na ciência, a descoberta do XIST. E eu estava lá no departamento de genética nesta época 
em que tinha o Projeto Genoma Humano no auge. Então era só ciência o tempo todo... O duro foi a volta, a volta foi crise total [risos].

\section{Você falou de um choque cultural. O que você quer dizer com isso?}

De tudo. Da quantidade de informação e de informações diferentes. Você estar numa cantina, você vê o fulano discutindo genética humana, a quantidade de informação em qualquer lugar que a gente ia... Nos seminários, na hora do almoço, sempre alguma palestra. Era uma informação por osmose, sabe? Ou seja, o tempo todo você fica ligada naquilo que está acontecendo. Saber que a ciência estava nesse nível... A gente aqui fazia coisas muito mais simples (Amanda, USP/RP).

Os centros aparecem como os locais em que são de fato realizadas as descobertas, onde estão os nomes importantes que realizaram essas descobertas, locais em que a ciência está na "ponta" e em que se vive a ciência o tempo todo, em comparação ao contexto brasileiro, em que se realizavam "coisas muito mais simples". Essa forte adesão ao que seria o ambiente efervescente e competitivo dos centros pode ser ponderada a partir da fala abaixo:

Outra coisa que eu notei, que é diferente, é que as relações deles [na Inglaterra] é mais de business, entre pesquisadores. Aqui a gente forma um grupo de amigos, os meus colegas de trabalho são meus amigos. Lá não, a impressão que eu tinha é que se conversava com um pesquisador só coisas relacionadas à pesquisa, era uma chatice. Se alguém te convidava para almoçar você já sabia que era para conversar de trabalho (Vanessa, UFRGS).

Nesse sentido, se para alguns dos entrevistados os centros são espaços em que se vive a ciência o tempo todo, em uma efervescência científica estimulante, que faz falta nos ambientes locais na periferia, outros percebem essa efervescência enquanto expressão de um nível muito alto de competitividade, correlato a um ritmo de trabalho constante e intenso. Assim, alguns pesquisadores destacam que se, de um lado, seu contexto 
local é de menor competição, de outro, isso propicia um ambiente de trabalho um pouco mais leve.

Pesquisadores seniores, ao comparar suas experiências de formação no exterior e no Brasil, destacam, também, o acesso à maior quantidade de informação, por meio das bibliotecas, com mais periódicos, que chegavam mais rapidamente do que no Brasil. Nesse sentido, o acesso ao conhecimento era facilitado ao se realizar um estágio fora do país. No entanto, a assimetria no acesso ao conhecimento é percebida como de alguma forma superada, primeiro, com o advento da internet e, segundo, o financiamento do acesso a revistas internacionais por intermédio do "Periódicos Capes". Nesse caso, uma demora anteriormente existente, a de acesso às novidades, às revistas, às descobertas, pôde ser superada:

A grande revolução que ajudou os países do terceiro mundo foi: primeiro, a internet. Antes, para a gente ter notícias de uma investigação determinada levava três meses para chegar a revista impressa aqui, agora, através da internet, a gente tem acesso à informação na hora. Então, isso nos coloca lado a lado com os nossos colegas do primeiro mundo (Joaquim, UFRGS).

Ao mesmo tempo, em um momento mais contemporâneo, um dos principais destaques para a experiência de pós-doutorado nos Estados Unidos, e que faz parte do que foi chamado de "choque cultural", foi a possibilidade de ter acesso mais direto ao conhecimento e às descobertas, para além de sua disponibilização em periódicos:

Lá não ficava só nos livros, nas revistas, lendo o que estava sendo descoberto. Se eu quisesse era só ir no laboratório do lado, aquilo que eu via num artigo, eu podia conhecer. Ou aquilo que eu ficava sempre, aqui no Brasil, só vendo na revista, na hora do almoço eu assistia um seminário e via a pessoa relatando aquela descoberta (Amanda, USP/RP).

As descrições das experiências internacionais remetem a um clima de imersão, que ganha materialidade no acesso a informações, mas que é mais do que isso: trata-se de um contato com um ambiente efervescente de pesquisa. Mais do que ler, todos ao mesmo tempo, um mesmo resultado de pesquisa, a experiência internacional em lugares nos quais se faz "pesquisa 
de ponta" significa entrar em contato direto com aqueles que realizaram as descobertas e escreveram os artigos nas revistas disponíveis na internet. $\mathrm{E}$ tem-se, também, a ideia de conseguir acesso às pesquisas - e, sobretudo, às novas técnicas, tecnologias e equipamentos - antes mesmo de elas serem divulgadas em publicações:

\section{E como você faz para se manter atualizada ou para buscar novas ideias?}

Duas coisas: congressos, eventos da área, e depois a gente vai às revistas científicas. Então eu leio o título dos artigos, ou resumos, da maior parte das revistas que são da minha área. Mas é importante ir ao congresso, porque na verdade você fica sabendo das coisas antes de elas serem publicadas. Você sabe as tendências, você sabe para onde a sua área está indo. É importante eleger pelo menos um ou dois eventos que sejam importantes na área, e que tenham não só aquilo que é apresentado do ponto de vista de conhecimento, mas também de avanço tecnológico, porque essa é uma área que depende muito de avanços tecnológicos. Então você vai ter, por exemplo, os fabricantes de equipamentos, que vão apresentar as novas técnicas, as novas tecnologias. [...]. Eu sei que tem muito pesquisador brasileiro que fala "eu gosto de ir ao congresso europeu", e é uma bobagem, sabe? Você pode ir ao congresso europeu, mas você vai para passear. Onde as coisas acontecem é no congresso americano (Sofia, Unicamp).

Na citação acima, o próprio congresso europeu - organizado pela European Society of Human Genetics - se torna, na fala da pesquisadora, periférico, se contraposto ao congresso organizado pela American Society of Human Genetics. Evidenciam-se, assim, possíveis estratificações percebidas no interior do espaço constituído pelos países considerados centrais para o desenvolvimento da pesquisa, sendo simplificador falar em uma periferia em termos absolutos, uma vez que até mesmo a Europa pode tornar-se, sob certas circunstâncias - nesse caso, o desenvolvimento tecnológico -, subalterna.

No que se refere ao ethos científico dos pesquisadores dos centros, tem-se a percepção de que são mais ambiciosos e competitivos, vistos como um exemplo a ser seguido: 
Eu acho que a competição lá [Estados Unidos] é mais clara. Se fala mais da competição, inclusive. Isso é uma coisa que no Brasil a gente é muito...

\section{Polido [risos].}

Muito polido, sim [...]. No lab meeting às vezes saía um paper de um grupo concorrente, aí o chefe italiano ficava louco, dizia "nós vamos ser roubados, nós vamos ser roubados". Parecia que tinham roubado a casa dele. Isso aqui é bem menos evidente, a gente ainda não é tão agressivo, a gente precisa ser mais agressivo (Diego, USP/RP).

Nesse sentido, os centros são percebidos como tendo pesquisadores com um perfil mais adequado a um espaço de grande competição pelas descobertas e publicações. Mais do que desenvolver as "ambições" de um pesquisador em contextos centrais, a experiência internacional de formação ou pesquisa é vista, de forma mais ampla, como um aprendizado de como pensar menos perifericamente:

Naquele momento [doutorado-sanduíche na Itália] acho que para mim foi muito importante entrar em contato com a visão que os pesquisadores tinham. [...] Foi a oportunidade de ver como essas pessoas pensavam, como era o delineamento experimental de um projeto [...].

\section{O que é essa "visão", exatamente?}

Quando você tem uma limitação de recurso, de tecnologia, você tende a trabalhar de acordo com o que é possível. Então, de certa forma, a gente condiciona o nosso raciocínio, o desenvolvimento dos projetos que a gente faz, de acordo com o ambiente em que está inserido. E a partir do momento em que você sai desse ambiente, você vai ter uma experiência fora, você entra em contato com um centro de referência, que está fazendo o que é possível ser feito, da melhor forma. Por quê? Porque eles têm acesso a recursos financeiros, à tecnologia, a equipamentos. Quando você se depara com esse cenário, que é totalmente favorável, você abre a sua cabeça: como desenho um projeto se eu não tenho nenhuma restrição? Acho que é um momento que 
você fica livre para pensar. Você percebe que a questão não é só tecnologia, pois ainda que você tenha algumas dificuldades, algumas restrições, já que no nosso país não temos o desenvolvimento tecnológico comparável ao que você tinha lá fora (naquela época, hoje em dia a gente avançou muito), você consegue ver que dá para fazer, que dá para desenvolver uma pesquisa, não exatamente igual, mas absolutamente comparável, mesmo em um país em desenvolvimento (Carolina, USP/RP).

Há diversos elementos importantes nessa citação, mas destaca-se aqui que ver - na prática - como a pesquisa é realizada por "referências mundiais", como são elaboradas as questões e o delineamento experimental de um projeto, como "essas pessoas pensam" permitiu, segundo a pesquisadora, visualizar como seria uma pesquisa elaborada sem nenhum dos elementos que caracterizariam justamente essa periferia pensada em termos de falta. Ir aos centros "abre a cabeça" para a ideia de que pesquisas nos moldes centrais podem ser realizadas nas periferias, ou, em outros termos, permite pensar de forma menos periférica. De todo modo, tem-se, também, a ideia de que uma agenda de pesquisa, elaborada em um cenário percebido como de escassez, é, de alguma forma, influenciada por esse mesmo cenário, que limita o raciocínio, as questões propostas e, também, o próprio pesquisador.

\section{Considerações finais}

Foram descritas, a partir da reunião de uma série de elementos - e citações - diferentes características da noção de uma periferia pensada, na comparação com os centros, em termos de falta. Mas, o que falta? Faltam dinheiro, equipamento, agilidade (ilustrada pela demora nas importações e pelos entraves burocráticos), pessoal técnico especializado para a realização de experimentos de rotina nos laboratórios e para a manutenção dos equipamentos. Faltam a rede elétrica estável (para que equipamentos sofisticados não sejam danificados, e problemas com o freezer não destruam as amostras), um serviço de secretaria que ajude a gerir o cotidiano da pesquisa - notadamente as compras, manutenção e prestação de contas -, faltam a "massa crítica", "material humano", uma maior concentração de pesquisadores e expertise, articulação, integração, 
coesão e especialização do trabalho. Falta, também, estar em contato com pessoas que realizam a pesquisa de ponta, estar em um "ambiente cultural" efervescente - e competitivo - que incentive pesquisas mais ambiciosas e a participação na corrida pelas descobertas, vista, em geral, como monopólio dos pesquisadores dos centros, os únicos que de fato participariam da corrida. Mesmo que os pesquisadores se considerem privilegiados no contexto nacional, se considerem fazendo pesquisa em "centros de excelência", os laboratórios visitados nos centros são vistos como espaços ideais para a realização da pesquisa na área.

Retomando o modelo de Keim (2010), é possível afirmar que esses diferentes elementos da comparação entre centros e periferias mobilizados pelos entrevistados podem ser alinhados às três dimensões propostas. Isso abrange tanto questões relativas à infraestrutura e à organização interna da produção do conhecimento quanto elementos que indicam uma forte dependência em relação às agendas de pesquisa centrais e, sobretudo, ao desenvolvimento tecnológico percebido como sempre vindo de fora. Inclui, ainda, elementos que atribuem um caráter central - passível de reconhecimento - às contribuições dos pesquisadores advindos dos centros, face à construção da produção de conhecimentos periféricos marginais, com poucas condições de participar da corrida - e competição - pelas descobertas científicas. Nesse sentido, tais articulações discursivas incidem tanto sobre os aspectos infraestruturais quanto cognitivos e de reconhecimento, sendo a falta uma espécie de denominador comum que expressa as diferentes assimetrias percebidas.

A partir das diferentes comparações mobilizadas pelos pesquisadores entrevistados, é possível elencar algumas dimensões das relações entre centros e periferias. A primeira dimensão reside no reconhecimento de que os centros são locais em que se vai para aprender, pois em seus laboratórios foram desenvolvidos os principais instrumentos, técnicas e tecnologias de pesquisa. O espaço nacional é visto, assim, como a arena para a recepção da ciência feita em outro lugar, no "cenário internacional", entendido, com frequência, como sinônimo de central. A segunda dimensão identificada é a articulação que imputa aos centros uma velocidade e uma efervescência ausentes no contexto periférico, descrito em termos de morosidade e 
isolamento. A terceira dimensão das relações entre centros e periferias incide mais diretamente sobre o tema da infraestrutura de pesquisa e, principalmente, do seu financiamento, em que os primeiros são vistos como tendo uma maior disponibilidade de recursos para a pesquisa, enquanto o contexto local é percebido como de escassez, ainda que pensada em termos relativos, se comparado a outros laboratórios brasileiros.

Essas e outras tantas oposições foram mobilizadas pelos pesquisadores entrevistados, ao serem solicitados a comparar suas experiências de trabalho no Brasil com suas experiências de formação e trabalho nos centros. Tais comparações, sempre tão duras e pouco mediadas, em que raramente se elencam características positivas para descrever o contexto brasileiro, levaram-me a formular a noção de periferia pensada em termos de falta, para sintetizar a percepção e a construção do contexto periférico. Foi em virtude do extenso trabalho de campo realizado que pude expressar desse modo as diferentes assimetrias que colocam os pesquisadores em posições periféricas. Pode-se mobilizar essa noção no estudo de outras disciplinas e contextos periféricos, entendida não como dimensão quantitativa - o quanto falta -, mas, sobretudo, como dimensão qualitativa, buscando retraçar o que falta aos diferentes contextos, auxiliando a montar um cenário mais complexo e preciso das relações entre centros e periferias na produção, circulação e legitimação do conhecimento científico.

Ao mesmo tempo, a noção de periferia pensada em termos de falta, mais do que um retrato fiel e objetivo das condições e desigualdades da produção do conhecimento em contextos periféricos, é uma articulação discursiva que contribui, também, para produzir centros e periferias. Não se trata de negar a existência de desigualdades na produção do conhecimento, mas marcar que essas diferenciações são postas e repostas nas falas dos entrevistados, influenciando suas percepções de si e de seus colaboradores internacionais, a definição de questões de pesquisa e a valorização e/ou desvalorização dos contextos de pesquisa. É interessante notar que características positivas do contexto local são mobilizadas pelos pesquisadores, mas geralmente não no momento da entrevista em que se discute em termos comparativos, indicando que os discursos de centros e periferias são naturalizados no cotidiano desses pesquisadores. 
Nesse sentido, a noção elaborada nesse artigo pode ser conjugada à discussão de "processos de centralização e periferização", tal como proposto por Neves $(2014 ;$ 2017). O autor afirma que a distinção centroperiferia é recorrentemente utilizada por pesquisadores brasileiros como critério de observação, que organiza seus contextos, expectativas e práticas, sendo os processos de periferização aqueles em que se atribui um valor negativo ao que se faz e como se faz, o que conduz a expectativas de não reconhecimento, não publicação, e de circulação restrita dos conhecimentos produzidos (Neves, 2014; 2017). Assim, é possível pensar a formulação em questão como outro elemento de um processo de periferização.

Destaco, por fim, que esta pesquisa encontrou quase todos os elementos da periferia pensada em termos de falta quando, em falas de pesquisadores situados na UFPA, houve a comparação de seu contexto local com experiências formativas e de trabalho em instituições brasileiras das regiões sul e sudeste, referindo-se a recursos financeiros, infraestrutura de pesquisa, profissionalização, quantidade de pesquisadores, especialização, velocidade, ou possibilidade de participação na competição internacional. Com isso, é possível fundamentar de que modo as percepções homólogas das relações entre centros e periferias são encontradas não somente em um mesmo país, o Brasil, mas em um conjunto restrito de centros de excelência. Esses achados fortalecem, portanto, a abordagem proposta, de que centros e periferias devem ser tomados como categoriais relacionais, e não cartográficas, cujo conteúdo empírico e analítico apenas se revela à medida que a investigação se aprofunda em áreas disciplinares e contextos locais e institucionais específicos.

Mariana Toledo Ferreira é Doutora em Sociologia pela Universidade de São Paulo (USP) e Professora do Instituto Federal de Educação, Ciência e Tecnologia de Goiás (IFG).

$\doteq$ marianatoledoferreira@gmail.com 


\section{Referências}

1. AKIWOWO, Akinsola. Universalism and indigenisation. Sociological theory: introduction. International Sociology, Londres, v. 3, n. 2, p. 155-60, 1988.

2. ALATAS, Syed F. Academic dependency and the global division of labour in the social sciences. Current Sociology, v. 51, n. 6, p. 599-613, 2003.

3. ANDERSON, Warwick; ADAMS, Vincanne. Pramoedya's chicken: postcolonial studies of technoscience. In: HACKETT, Edward et al. (Orgs.) The New Handbook of Science and Technology Studies. Cambridge: MIT Press, 2008, p. 181-204.

4. ARVANITIS, Rigas. La division internationale du travail scientifique. Dossier édité par Terry Shinn, Dominique Vellard et Roland Waast, Cahiers de la recherche sur l'éducation et les savoirs. Revue d'Anthropologie des Connaissances, v. 5, n. 3, p. 635-7, 2011 a.

5. ARVANITIS, Rigas. Que des réseaux! Compte rendu de Caroline Wagner. The new invisible college. Science for development. Revue d'Anthropologie des Connaissances, v. 5, n. 1, p. 178-85, 2011 b.

6. BASALLA, George. The spread of Western science. Science, v. 156, n. 3775 , p. 611-22, 1967.

7. BEIGUELMAN, Bernardo. Genética de populações humanas. Ribeirão Preto: SBG, 2008.

8. CARDOSO, Fernando H.; FALETTO, Enzo. Dependência e desenvolvimento na América Latina: ensaio de interpretação sociológica. Rio de Janeiro: Zahar Editores, 1970.

9. CARLOTTO, Maria C.; GARCIA, Sylvia G. Novos saberes, novas hierarquias: disputas contemporâneas em torno da profissão acadêmica. Revista Brasileira de Ciências Sociais, v. 33, n. 96, p. 1-19, 2017.

10. CHAKRABARTY, Dipesh. Provincializing Europe: postcolonial thought and historical difference. New Jersey: Princeton University Press, 2000.

11. CORREA, Marilena V. O admirável Projeto Genoma Humano. Physis. Revista de Saude Coletiva, v. 12, n. 2, p. 277-99, 2002.

12. DESLAURIERS, Jean-Pierre; KÉRISIT, Michèle. O delineamento de pesquisa qualitativa. In: POUPART, Jean et al. (Orgs.). A pesquisa qualitativa: enfoques epistemológicos e metodológicos. Petrópolis: Vozes, 2008. p. 127-53.

13. FERREIRA, Mariana T. A institucionalização da pesquisa em genética no Brasil e seus pesquisadores: um estudo de caso do Centro de Estudos do Genoma Humano da USP. Dissertação (Mestrado em Sociologia). Faculdade de Filosofia, Letras e Ciências Humanas, Universidade de São Paulo, São Paulo, 2013.

14. GAILLARD, Jacques. La naissance difficile des communautés scientifiques. In: SALOMON, Jean-Jacques et al. (Orgs.). La quête incertaine : science, technologie et développement. Nova York, Paris: Economica, 1994, p. 213-49. 
15. GAILLARD, Jacques. Measuring research and development in developing countries: main characteristics and implications for the Frascati Manual. Science, Technology \& Society. v. 15, n. 1, p. 77-111, 2010.

16. HERRERA, Amílcar. Ciencia y política en América Latina. México: Siglo Veintiuno, 1971.

17. HOUNTONDJI, Paulin J. Scientific dependence in Africa today. Research in African Literatures, v. 21, n. 3, p. 5-15, 1990.

18. KEIM, Wiebke. Aspects problématiques des relations internationales en sciences sociales: pour un modèle centre-périphérie. Revue d'Anthropologie des Connaissances, v. 4, n. 3, p. 570-98, 2010.

19. KREIMER, Pablo. Ciencia y periferia: nacimiento, muerte y resurrección de la biología molecular en la Argentina. Buenos Aires: Eudeba, 2010.

20. L'HOSTE, Ana S.; HUBERT, Matthieu. Mobilité scientifique et réflexivité des chercheurs: comment les déplacements façonnent des modes de production de connaissances. Revue d'anthropologie des connaissances, v. 6, n. 2, p. 357-80, 2012.

21. LAW, John. On sociology and STS. The Sociologial Review. v. 56, n. 4, p. 623-49, 2008.

22. LOSEGO, Philippe; ARVANITIS, Rigas. La science dans les pays non hégémoniques. Revue d'Anthropologie des Connaissances, v. 2, n. 3, p. 33442, 2008.

23. MEDINA, Leandro R. Centers and peripheries in knowledge production. Nova York: Routledge, 2013.

24. MENEGHINI, Rogério; PACKER, Abel. Articles with authors affiliated to Brazilian institutions published from 1994 to 2003 with 100 or more citations: II - identification of thematic nuclei of excellence in Brazilian science. Anais da Academia Brasileira de Ciências, v. 78, n. 4, p. 841-53, 2006.

25. NEVES, Fabrício M. A contextualização da verdade ou como a ciência tornase periférica. Civitas, v. 14, n. 3, p. 556-74, 2014.

26. NEVES, Fabrício M. Alguns elementos do regime de administração da irrelevância. Anais do 180 Congresso Brasileiro de Sociologia. Brasília, 2017. Disponível em: <http://sbs2017.com.br/anais/resumos/ PDF-eposter-trabaceito-1153-2.pdf $>$.

27. NUNES, João Arriscado; GONÇALVES, Maria Eduarda. Introdução. In: NUNES, João A.; GONÇALVES, Maria E. (Orgs.). Enteados de Galileu? A semiperiferia no sistema mundial da ciência. Porto: Edições Afrontamento, 2001, p. 13-31.

28. POLANYI, Michael. The republic of science and its political and economic theory. Minerva, v. 1, p. 54-73, 1962.

29. SAID, Edward W. Orientalism. Nova York: Pantheon Books, 1978. 
30. SANTOS, Boaventura de S. Para além do pensamento abissal: das linhas globais a uma ecologia de saberes. In: SANTOS, Boaventura de S.; MENESES, Maria Paula. Epistemologias do Sul. São Paulo: Cortez, 2010, p. 31-83.

31. SHINN, Terry. Division du savoir et spécificité organisationnelle. Les laboratoires de recherche industrielle en France. Revue Française de Sociologie, v. 21, n. 1, p. 3-35, 1980.

32. STRATHERN, Marilyn. Melhorar a classificação. A avaliação no sistema universitário britânico. Novos Estudos, n. 53, p. 15-31, 1999.

33. STRAUSS, Anselm; CORBIN, Juliet. Pesquisa qualitativa: técnicas e procedimentos para o desenvolvimento de teoria fundamentada. Porto Alegre: Artmed, 2008.

34. TRAWEEK, Sharon. Big science and colonialist discourse: building high-energy physics in Japan. In: GALISON, Peter; HEVLY, Bruce. Big science: the growth of large-scale research. Stanford: Stanford University Press, 1992, p. 100-28.

35. VARSAVSKY, Oscar. Por uma política científica nacional. Rio de Janeiro: Paz e Terra, 1976. 
Recebido: 25 out. 2018 Aceite final: 27 nov. 2018 